\title{
ESTUDO DE CASO: UMA REFLEXÃO SOBRE A APLICABILIDADE EM PESQUISAS NO BRASIL
}

\section{CASE STUDY: A CONSIDERATION ABOUT THE APPLICABILITY ON RESEARCH IN BRAZIL}

\author{
GILBERTO ANDRADE MARTINS \\ Professor Livre Docente da Universidade de São Paulo e \\ Professor Titular do Departamento de Contabilidade e Atuária da Faculdade de Economia, \\ Administração e Contabilidade da Universidade de São Paulo \\ E-mail: martins@usp.br
}

\begin{abstract}
Resumo
É cada vez mais freqüente a condução de pesquisas científicas orientadas por avaliações qualitativas: pesquisas qualitativas, como são geralmente denominadas. A estratégia de pesquisa discutida neste texto - Estudo de Caso - pede avaliação qualitativa, pois seu objetivo é o estudo de uma unidade social que se analisa profunda e intensamente. Busca-se apreender a totalidade de uma situação e, criativamente, descrever, compreender e interpretar a complexidade de um caso concreto, mediante um mergulho profundo e exaustivo em um objeto delimitado. Estudos epistemológicos têm mostrado que um grande número de pesquisas orientadas por Estudo de Caso apresenta sérias deficiências: análises intuitivas, primitivas e impressionistas, não conseguindo transcenderem a simples relatos históricos, obviamente muito afastados do que se espera de um trabalho científico. São diversas as fontes de erros que comprometem um Estudo de Caso. 0 objetivo deste artigo é levantar e discutir limitações da prática do Estudo de Caso conforme concebida por Robert Yin, fundamentalmente, devido às enormes diferenças das condições de infra-estrutura dos pesquisadores brasileiros quando comparados aos investigadores norte-americanos. São tratadas as limitações quanto ao tipo de estudo, casos únicos $x$ casos múltiplos, equipes de colaboradores, tempo e recursos financeiros.
\end{abstract}

Palavras-chave: estudo de caso; pesquisa científica qualitativa; pesquisa no Brasil.

\section{Abstract}

It is more and more frequent to conduct scientific research based on qualitative evaluations, usually named qualitative research. The research strategy discussed on this paper - Case Study - asks for qualitative evaluation as its objective is the study of a social unity that is deeply and intensely analyzed. We seek to apprehend the situation in its whole and describe, comprehend and interpret a concrete case complexity in a creative way, by an exhausting and deep diving into a bounded object. Epistemological studies have been showing that a great number of researches oriented by Case Studies present serious deficiencies: intuitive, primitive and impressionistic analysis, that cannot transcend mere historical reports, obviously very far from what is aimed from a scientific work. There are several sources of mistakes that compromise a Case Study. The objective of this paper is to raise and discuss the limitations of the Case Study as it is conceived by Robert Yin, especially due to the enormous difference between Brazilian researchers' infrastructure condition and the North American ones. We deal with the limitations of the type of study, single cases $\mathrm{x}$ multiple cases, collaborators' staff, time and financial resources.

Key words: case study, scientific research based on qualitative, research in Brazil. 


\section{INTRODUÇÃO}

Publicada originalmente em 1994, a obra de Robert Yin (2001) vem se tornando, no decorrer dos anos, um modelo único para a aplicação do Estudo de Caso como estratégia para condução de pesquisas que irão compor artigos, dissertações e teses em todas as áreas do conhecimento, particularmente, nas Ciências Sociais Aplicadas. Um verdadeiro vade-mécum, pela excelência de seu conteúdo e formato. 0 referido texto tem o mérito de estabelecer um conjunto de procedimentos seqüenciais racionais para o emprego de uma estratégia de pesquisa que vem sendo aplicada há 2.300 anos (BONOMA, 1985, p. 199) e cujos procedimentos, surpreendentemente, ainda não tinham sido convencionados de forma adequada.

Entretanto, longe de pôr um ponto-final no assunto, a proposta de Yin certamente oferece diversos parâmetros para se pensar e discutir o método, pois foi concebida a partir de uma experiência pessoal e de um contexto específico, que é o aparato burocráticocientífico norte-americano contemporâneo, cuja dotação orçamentária é dramaticamente superior aos recursos econômicos existentes nos demais países de Primeiro Mundo. Se pensarmos sobre a nossa realidade de país emergente, a lacuna torna-se ainda maior.

0 modelo de pesquisa concebido por Yin, como poderemos ver nesta exposição, precisa ser avaliado sob os parâmetros da pesquisa acadêmica brasileira, principalmente, nos níveis de mestrado e doutorado. Isso não implica, a priori, mudanças no arcabouço metodológico proposto pelo autor, mas sim um redimensionamento dos projetos de pesquisa brasileiros que pretendam adotar tal estratégia de pesquisa.

A partir da década de 1990, até nossos dias, tem havido um extraordinário crescimento de trabalhos científicos orientados por um estudo de caso, particularmente, nas Ciências Sociais Aplicadas. Roesch (1999), em levantamento sobre dissertações de mestrado do Programa de Pós-Graduação em Administração da Universidade Federal do Rio Grande do Sul, constatou que, de um total de 107 trabalhos, 52,1\% eram constituídos por estudos de caso único. Silva (2002) realizou um levantamento no Núcleo de Pós-Graduação da Universidade Federal da Bahia e constatou que, de um total de 72 trabalhos aprovados entre 1999 e 2001, 74\% utilizaram o estudo de caso como estratégia de pesquisa. Gil (2005) investigaram os delineamentos das pesquisas apresentados no ENANPAD de 2002. Dos 542 trabalhos resultantes de pesquisas ou ensaios, na forma de artigos, 268 foram considerados com abordagens empírico-teóricas, sendo 90 - 33,5\% - estudos de caso. Os autores concluíram ainda que os estudos de caso vêm sendo utilizados para investigação em todas as áreas da Administração e afirmaram que os aspectos mais críticos relativos aos resultados obtidos referem-se à utilização de poucas fontes de evidência na maioria das pesquisas e à falta de clareza nos procedimentos analíticos, com poucos trabalhos caracterizados pela aplicação de procedimentos rigorosos. Aliás, diversos textos têm apontado sérias deficiências sobre a prática desta, tão comum, estratégia de pesquisa.

Dentre outros duvidosos arranjos metodológicos, um estudo de caso não deve ser entendido como um longo histórico de uma unidade organizacional, acompanhado de algumas tabelas que mostram apenas percentuais, geralmente, para encobrir respostas de poucos participantes, sobre variáveis imprecisas; não é fazer o levantamento de dados secundários sobre uma organização, geralmente uma grande empresa, e com esse material, comumente extraído do site da empresa, ou banco de dados público, construir um estudo de caso; não é o pesquisador enviar questionários para um grande número de empresas, obter poucas respostas e, a partir daí, montar seu estudo multicaso; não é sinônimo de exemplo, em situações em que o autor desenvolve um texto teórico com procedimentos para eventuais aplicações e, ao final, apresenta um exemplo, denominando-o de estudo de caso, e o que é mais preocupante, às vezes, qualifica-o de 
estudo de caso real; não é o desenvolvimento e adequação de uma técnica, método ou modelo aplicados em uma única organização. Ou seja, a utilização de falso estudo de caso para verificar se são adequadas, ou válidas, teorias explícitas em uma técnica, método ou modelo a uma situação particular.

Infelizmente a estratégia de pesquisa orientada por um estudo de caso, em muitas investigações na área de Ciências Sociais Aplicadas, não tem sido aplicada de acordo com o que se espera de um trabalho científico. 0 estudo de caso é próprio para a construção de uma investigação empírica que pesquisa fenômenos dentro de seu contexto real - pesquisa naturalística - com pouco controle do pesquisador sobre eventos e manifestações do fenômeno. Sustentada por uma plataforma teórica, reúne o maior número possível de informações, em função das questões e proposições orientadoras do estudo, por meio de diferentes técnicas de levantamento de informações, dados e evidências. Como se sabe, a triangulação de informações, dados e evidências garante a confiabilidade e a validade dos achados do estudo. Busca-se, criativamente, apreender a totalidade de uma situação identificar e analisar a multiplicidade de dimensões que envolvem o caso - e, de maneira engenhosa, descrever, compreender, discutir e analisar a complexidade de um caso concreto, construindo uma teoria que possa explicá-lo e prevê-lo.

Mediante um mergulho profundo e exaustivo em um objeto delimitado, o estudo de caso possibilita a penetração em uma realidade social, não conseguida plenamente por um levantamento amostral e avaliação exclusivamente quantitativa. 0 trabalho de campo estudo do caso - deverá ser precedido por um detalhado planejamento, a partir de ensinamentos advindos do referencial teórico e das características próprias do caso. Incluirá a construção de um protocolo de aproximação com o caso e de todas as ações que serão desenvolvidas até se concluir o relatório do estudo. 0 protocolo se constitui em um conjunto de códigos, menções e procedimentos suficientes para se replicar o estudo, ou aplicá-lo em outro caso que mantém características semelhantes ao estudo de caso original. O protocolo oferece condição prática para se testar a confiabilidade do estudo, isto é, obterem-se resultados assemelhados em aplicações sucessivas a um mesmo caso. 0 estudo de caso orientado por um planejamento e protocolo não se reduz a uma coleção de dados e informações que não oferecem condições seguras sobre os achados do estudo. É preciso contar com a permissão formal do principal responsável pela unidade em estudo. 0 papel do pesquisador deve ser claro para aqueles que the prestam informações, não podendo ser confundido com elementos que inspecionam, avaliam ou supervisionam atividades.

Em um estudo de caso, análises e reflexões estão presentes durante os vários estágios da pesquisa, particularmente quando do levantamento das informações, dados e evidências, em situações em que resultados parciais sugerem alterações, correções de rumo. A sistematização e organização de rascunhos, notas de observações, transcrições, registros de comentários, diários, opiniões etc. são coligidos em campo e indexados segundo algum critério definido no protocolo do estudo. Para tanto, o pesquisador deverá, cotidianamente, construir seu diário de campo, ou diário da pesquisa.

Estudos epistemológicos sobre a produção do campo das Ciências Sociais Aplicadas têm mostrado que um grande número de pesquisas orientadas por estudo de caso apresenta sérias deficiências: análises intuitivas, primitivas e impressionistas, não conseguindo transcenderem a simples relatos históricos, obviamente muito afastados do que se espera de um trabalho científico. São diversas as fontes de erros que comprometem um Estudo de Caso. Pensar que um estudo de caso é de fácil condução é um grande engano. Uma pesquisa orientada por essa estratégia exige perseverança e engenhosidade. Pode-se, nestas circunstâncias, aplicar o paradoxo de que: quanto mais fácil for uma estratégia de pesquisa, mais difícil será sua realização.

$\mathrm{O}$ objetivo deste artigo, portanto, é ajudar os pesquisadores acadêmicos nacionais a 
empreenderem inquirições cientificamente consistentes de Estudo de Caso sob a prescrição metodológica da obra de Robert Yin sem perder de vista a realidade nacional, particularmente, dos Programas de Pós-Graduação.

\section{ESTUDO DE CASO: HISTÓRICO E DEFINIÇÕES}

Estudo de caso é uma estratégia metodológica de se fazer pesquisa nas ciências sociais e nas ciências da saúde. Trata-se de uma metodologia aplicada para avaliar ou descrever situações dinâmicas em que o elemento humano está presente. Busca-se apreender a totalidade de uma situação e, criativamente, descrever, compreender e interpretar a complexidade de um caso concreto, mediante um mergulho profundo e exaustivo em um objeto delimitado. Para Goode e Hatt (1999, apud LAZZARINI 1995, p.17), a técnica é "um modo de organizar os dados em termos de uma determinada unidade escolhida".

Trata-se de uma metodologia válida, conforme podemos ver em Yin (2001, p. 24), nas situações em que as questões a serem respondidas são do tipo "como?" ou "por que?", quando o pesquisador tem pouco controle sobre os eventos e em situações nas quais o foco se encontra em fenômenos complexos e contemporâneos, inseridos no contexto da vida real.

0 método surgiu na Medicina há mais de dois mil anos, quando o grego Hipócrates (460?-377 a.C.) relacionou 14 casos clínicos. Trata-se, portanto, de uma das mais antigas formas de investigação científica conhecida e cuja aplicação extrapola sua seara original, chegando a campos como o jornalismo, a administração, a contabilidade, a economia, a educação etc. Em termos amplos, essa técnica é também considerada uma forma válida de se manter registros, principalmente na Medicina, no Direito e no Serviço Social.

Conforme exposto, o Estudo de Caso é uma das metodologias mais antigas na investigação científica; mas teve seu primeiro esforço de estabelecimento de protocolos para uma prática unificada em 1994, quando a obra de Yin veio a público. Desde então, o referido texto vem se tornando referência básica para investigações sob este método. A preferência é justificável não apenas pelo pioneirismo, mas também pela consistência normativa dos procedimentos propostos pelo autor.

A fixação de parâmetros para a investigação no Estudo de Caso, entretanto, merece reparos de nossa parte e uma reflexão sobre o contexto brasileiro da pesquisa social. A obra de Yin, calcada na experiência do autor, privilegia a aplicação da metodologia por meio de equipes de pesquisadores, relegando a um segundo plano a possibilidade de execução do processo de inquirição em um nível individual. Este é um dos aspectos que nos leva a concluir que a referida proposta ainda demanda uma contextualização para o cenário brasileiro, pois a tradição de investigação científica no país, particularmente, no que se refere aos cursos de mestrado e doutorado, configura-se como uma investigação solitária, e não coletiva.

Ainda na abordagem de Yin, o Estudo de Caso como ferramenta de investigação científica é utilizado para compreender processos na complexidade social nas quais estes se manifestam: seja em situações problemáticas, para análise dos obstáculos, seja em situações bem-sucedidas, para avaliação de modelos exemplares (Yin (2001, p. 21). A metodologia pressupõe, em alguns casos, a existência de uma teoria prévia, que será testada no decorrer da investigação (Idem, p. 49), e admite em outros casos a construção de uma teoria a partir dos achados da pesquisa.

Para Yin, há pelo menos cinco situações em que o Estudo de Caso se aplica: para explicar vínculos causais em intervenções na vida real que são muito complexas para 
estratégias experimentais; quando é preciso descrever intervenções no contexto em que ocorrem; para ilustrar determinados tópicos em uma investigação; para explorar uma situação complexa de resultados e como uma forma de meta-avaliação de determinados processos. Yin afirma que a prática de Estudo de Caso é extremamente complicada e, paradoxalmente, afirma com muita autoridade que quanto mais fácil for a estratégia de pesquisa, mais difícil será realizá-la.

Com esta complexidade na investigação de Estudo de Caso, adverte Yin, o pesquisador se depara com uma situação incomum, na qual existem muito mais variáveis de interesse do que dados fornecidos de forma objetiva e imparcial. 0 pesquisador também deve estar preparado para fazer uso de várias fontes de evidências, que precisam convergir, oferecendo, dessa maneira, condições para se afirmar fidedignidade e validade dos achados por meio de triangulações de informações, dados, evidências e mesmo de teorias. Para desenvolver sua investigação, o estudioso deve se valer de uma plataforma de proposições teóricas para conduzir a coleta e a análise de dados, eventos que ocorrem, paralelamente, ao longo de toda a investigação.

Segundo Robert Yin, há quatro tipos de Estudo de Caso possíveis: o caso único com enfoque holístico, o caso único com enfoque incorporado e os casos múltiplos com os mesmos enfoques, como podemos ver no diagrama abaixo:

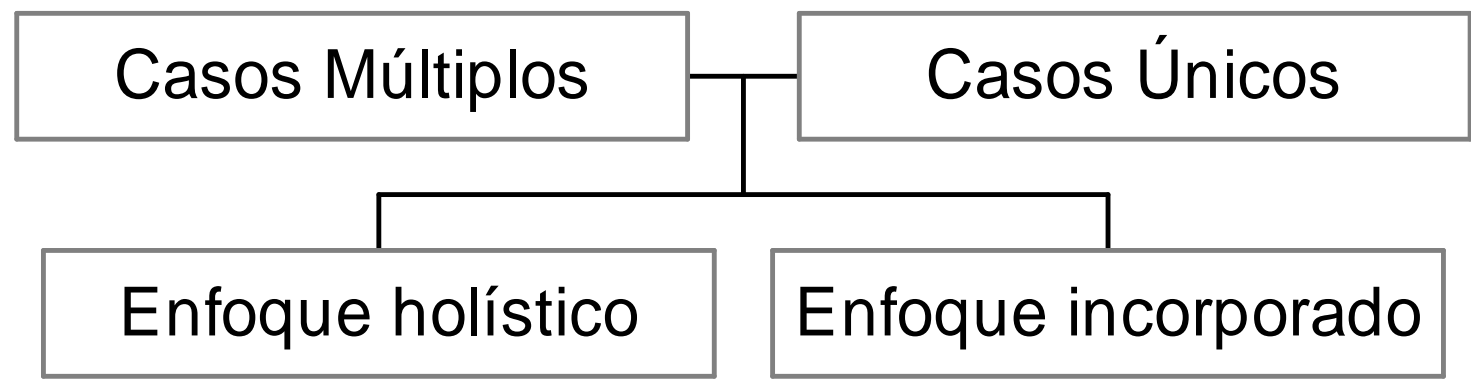

\subsection{CASOS ÚNICOS X CASOS MÚLTIPLOS}

Yin prescreve táticas diferenciadas para cada tipo de Estudo de Caso. Em relação ao Estudo de Caso único, o autor o prescreve quando este representa o caso decisivo para testar uma teoria bem formulada, seja para confirmá-la, seja para contestá-la, seja ainda para estender a teoria. Nesta situação, o caso único deve satisfazer todas as condições para testar a teoria.

Uma segunda justificativa para um Estudo de Caso único é quando representa uma situação rara ou extrema. Essa situação é muito mais comum no âmbito da saúde e é usada para casos patológicos incomuns.

A terceira situação é quando o caso único se mostra revelador, quando o pesquisador tem a chance de observar um fenômeno anteriormente inacessível à investigação científica.

Uma quarta alternativa é quando o Estudo de Caso único é utilizado como introdução a um estudo mais apurado ou, ainda, como caso-piloto para a investigação.

O maior risco do Estudo de Caso único é que a explicação científica peque por fragilidade, devido a possíveis incidências de fenômenos encontrados apenas no universo pesquisado, comprometendo a confiabilidade dos achados. Em qualquer das alternativas, o 
pesquisador deverá compor um quadro que corresponda à teoria revelada pelo estudo do caso, isto é, construir uma teoria que explique e preveja o fenômeno investigado.

Em relação aos Estudos de Casos múltiplos, Yin afirma que estes costumam ser mais convincentes (2001, p. 68). O mesmo autor repreende aqueles que não consideram os Estudos de Casos múltiplos como Estudo de Caso.

Yin afirma que uma das chaves para se construir um Estudo de Caso múltiplo bemsucedido é que este obedeça a uma lógica de replicação (Idem, p. 68), e não a da amostragem, que "exige o cômputo operacional do universo ou do grupo inteiro de respondentes em potencial e, por conseguinte, o procedimento estatístico para se selecionar o subconjunto específico de respondentes que vão participar do levantamento" (Idem, p. 70). Mais adiante, o autor complementa:

[...] os Estudos de Caso, em geral, não devem ser utilizados para avaliar a incidência de fenômenos [...] um Estudo de Caso teria que tratar tanto do fenômeno de interesse quanto de seu contexto, produzindo um grande número de variáveis potencialmente relevantes. (Idem, p. 71).

No diagrama seguinte, podemos ver a concepção de Yin para a elaboração de um fluxograma para um Estudo de Caso múltiplo:

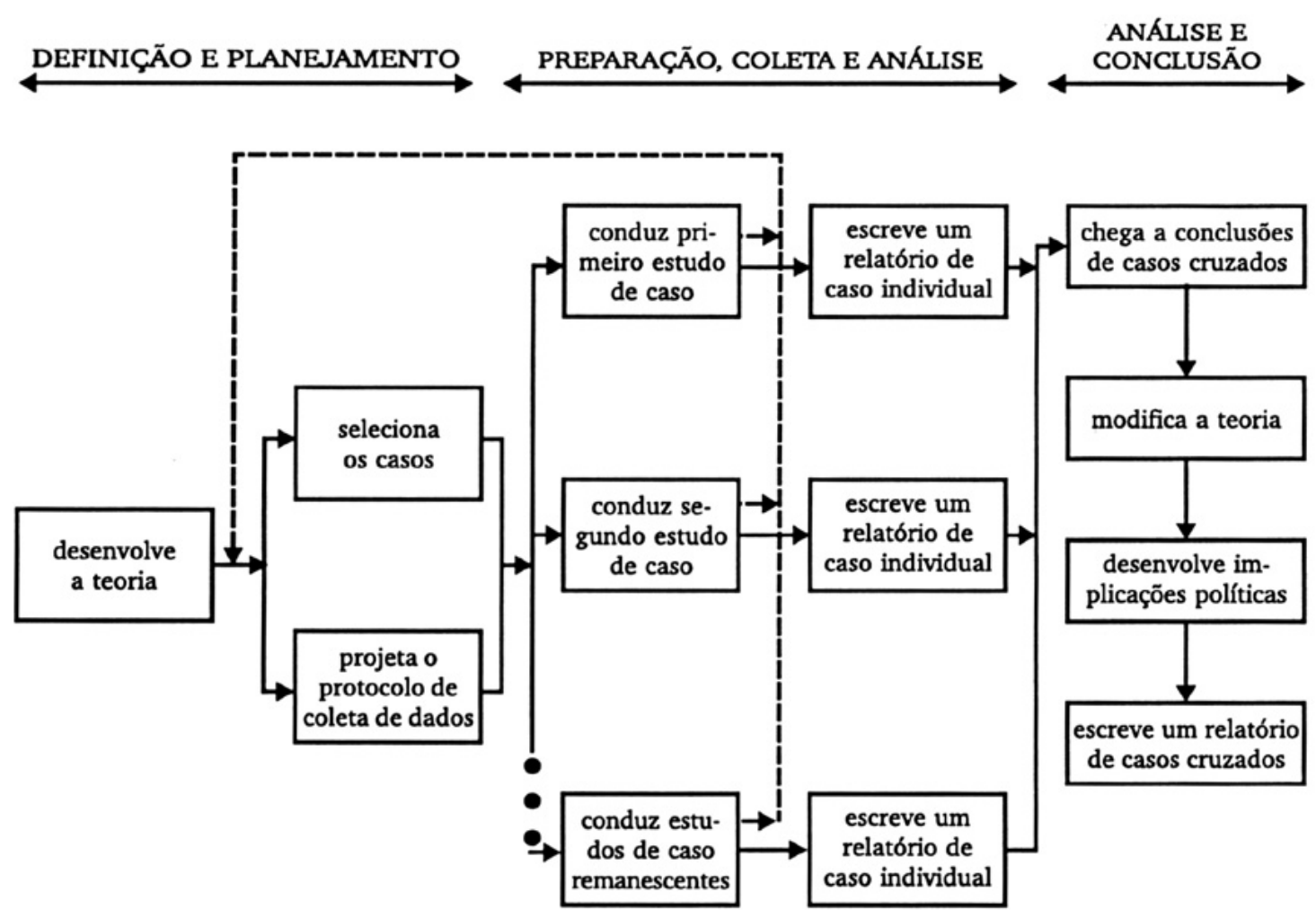

Fonte: YIN (2001)

O autor adverte que o Estudo de Caso múltiplo implica muito tempo e dinheiro, muito mais que "um estudante ou um pesquisador de pesquisa independente possuem" (Idem, p. 68). Neste trecho, como podemos ver, o autor desautoriza, de modo eufemístico, a possibilidade de um empreendimento nestes moldes ser realizado por um indivíduo.

Nesta situação - de Estudos de Casos múltiplos - a análise deve seguir um experimento cruzado. Cada caso deve ser selecionado de modo a prever resultados semelhantes ou, inversamente, produzir resultados contrastantes por razões previsíveis. A “lógica da replicação” pressupõe uma rica estrutura teórica. Yin ressalta: "a estrutura 
teórica torna-se mais tarde o instrumento para generalizar para casos novos" (Idem, p. 69). Tem-se, nessas condições, a possibilidade de construção de uma teoria (grounded theory) a partir dos resultados comuns aos casos analisados. Generaliza-se uma teoria para explicar e prever fenômenos assemelhados, e não variáveis conforme estudos amostrais.

\subsection{A PESQUISA INDIVIDUAL NO ESTUDO DE CASO}

Devido às próprias limitações das pesquisas acadêmicas no Brasil, sobretudo em relação ao aspecto solitário de nossos pesquisadores, achamos por bem focar na análise da pesquisa individual no Estudo de Caso para, mais tarde, fundamentarmos como a modalidade mais adequada para o nosso contexto.

Com base nos pressupostos de Yin já descritos neste artigo, percebemos que o raciocínio do autor constrói certamente um rol de procedimentos rigorosos que tornam a pesquisa de Estudo de Caso consistente cientificamente, isto é, replicável e dotada de um rol de procedimentos consistente para a mensuração dos resultados. 0 método, contudo, relegou a um segundo plano a perspectiva da aplicação de uma pesquisa individual. Devemos, neste caso, ter em mente que as obras de Hipócrates e Freud são exemplos felizes de inquiriçõos individuais sob este método.

É certo também que o autor cita diversos exemplos consistentes de pesquisa de Estudo de Caso bem-sucedidas que tiveram sua origem na investigação individual. É o caso da obra Street Corner Society (Yin, 2001, p. 22), do sociólogo William E. Whyte, citado pelo autor como "um exemplo clássico de um Estudo de Caso descritivo"; The Urban Villagers, de Herbert Gans (Idem, p. 117), o qual o autor elogia como exemplo feliz de aplicação da metodologia ou Essence of Decision: Explaining the Cuban Missile Crisis (Idem, p. 23), de Graham Allison, apresentado também como modelo de pesquisa sob a metodologia. Ainda a título de exemplo, poderiam ser citados Tally's Corner, de Elliot Liebow (Idem, p. 64), o livro, admite o autor, "apresenta impressões de uma subcultura que durante muito tempo predominou em muitas cidades americanas, mas cuja compreensão nunca foi muito clara". A pesquisa The Forest Ranger: A Study in Administrative Behavior (1960), Estudo de Caso desenvolvido individualmente por Herbert Kaufman (Idem, p. 185), é apontada também como exemplo para os pesquisadores interessados em aplicar o método.

Todas as obras até aqui citadas referem-se a casos únicos com enfoques incorporados, mas o autor chega a citar um caso de um único pesquisador que realizou um caso múltiplo de enfoque incorporado: a obra The Dynamics of Bureaucracy, de Peter Blau (Idem), que compara a organização formal e informal de grupos de trabalho em duas instituições, uma pública e outra privada. Yin chega a usá-la como exemplo

[...] de como um pesquisador habilidoso pode tirar proveito de oportunidades inconstantes e de alterações nas relações teóricas, a fim de produzir um Estudo de Caso clássico. Ao admitir isso, o autor implicitamente nega sua asserção de que o Estudo de Caso múltiplo implica muito tempo e dinheiro, muito mais que um estudante ou um pesquisador de pesquisa independente possuem (Idem, p. 83).

0 autor, da mesma forma, destaca a importância da contemporaneidade quando o método é o Estudo de Caso - Yin afirma: "o Estudo de Caso é uma estratégia escolhida ao se examinarem acontecimentos contemporâneos" (Idem, p. 27) -, mas cita, entre os exemplos, uma pesquisa histórica: The Anatomy of a Revolution (Idem, p. 51), de 1938, que comparou as revoluções inglesa (século XVII), francesa (século XVIII), norte-americana (século XVIII) e russa - esta última, deflagrada em 1917, foi a única que ocorrera em um 
período relativamente recente. A obra, inclusive, é citada como um exemplo de Estudo de Caso múltiplo com enfoque incorporado, o que sinaliza, por meio da sanção do autor, a potencialidade do uso de casos históricos como ingredientes de uma pesquisa de Estudo de Caso contemporânea.

O estudo de caso incorporado é aquele no qual a situação é avaliada a partir de diferentes unidades ou níveis de análise, que podem ser setores diferentes de uma determinada instituição (setor de vendas e setor de produção, por exemplo), podem ser atividades (processo de planejamento e processo de implantação, por exemplo). Cada um dos níveis de análise ou unidades pode ser analisado com critérios distintos.

Um risco a se levar em conta na pesquisa de estudo de caso incorporado é a perda da visão do todo no processo a ser estudado. Como exemplo, Yin cita:

[...] o estudo do clima organizacional pode apresentar os funcionários em si como subunidades de estudo. No entanto, se os dados puserem em evidência somente os funcionários, o estudo se transformará, na verdade, em uma investigação sobre o emprego e não sobre a organização. 0 que aconteceu é que os fenômenos originais de interesse [sic] (o clima organizacional) tornaram-se o contexto, não o objetivo do estudo. (Idem, p. 83)

0 estudo de caso holístico deve ser aplicado quando não é possível identificar uma "subunidade lógica". O maior risco dos projetos holísticos é que eles podem levar o pesquisador a ignorar pontos importantes de um processo, por não isolá-los em unidades lógicas. Evidentemente, para qualquer abordagem metodológica, será preciso delimitar o campo de trabalho, os limites considerados no estudo. Esse recorte vai se construindo ao longo do estudo, sendo raro uma definição inicial ser mantida até o término do trabalho.

Outro risco é que uma mudança de situação no caso investigado pode obrigar o pesquisador a refazer o trabalho. Para evitar ou minimizar esse risco, Yin sugere a construção de subunidades lógicas (Ibid).

\section{PROPOSTA METODOLÓGICA NO CONTEXTO NACIONAL}

Fundamentados na proposta pioneira de Yin, formulada sob uma rigorosa metodologia - apesar das observações e limitações feitas até aqui -, julgamos conveniente sugerir uma adequação dessa estratégia de pesquisa ao cenário brasileiro.

A primeira peculiaridade a se destacar é a característica artesanal da pesquisa desenvolvida, particularmente, na área de Ciências Sociais Aplicadas, construídas no país. Chamamos de artesanal pois, pela nossa própria experiência acadêmica, testemunhamos o isolamento do pesquisador acadêmico brasileiro ao empreender sua inquirição científica aliado ao baixo volume da produção científica, e a comprometedora qualidade destes trabalhos.

As pesquisas de mercado, inversamente, são uma verdadeira indústria nos EUA, com institutos de pesquisa como Yankee Group, IDC e ATKearney. Para este segmento, a proposta de Yin se adéqua com muito mais facilidade, pelos altos investimentos e grandes equipes para o desenvolvimento de Estudo de Caso.

Sobre equipes, Yin chega a afirmar que "uma investigação de Estudo de Caso deve contar com vários pesquisadores" (Idem, p. 85). No Brasil, isso se mostra atualmente pouco praticável. Por isso defendemos que uma abordagem acrítica dos preceitos de Yin é problemática no Brasil, no que tange ao âmbito acadêmico. 
Além dos aspectos já citados (pesquisas artesanais e número de pessoas envolvidas) é importante aprofundar em mais dois itens fundamentais para a pesquisa de Estudo de Caso, que inviabilizam grande parte das iniciativas brasileiras: tempo e dinheiro.

Primeiramente, a questão do tempo limita o leque de possibilidades de investigação orientada por um Estudo de Caso. Segundo a Portaria 52, de 26 de setembro de 2002, da Coordenação de Aperfeiçoamento de Pessoal de Nível Superior (Capes), no seu artigo $9^{\circ}$, define que a bolsa concedida pela entidade tem o prazo de 12 meses, podendo "ser renovada anualmente até atingir o limite de 48 (quarenta e oito) meses para o doutorado, e de 24 (vinte e quatro) meses para o mestrado" (PORTARIA No 52, 2002). Tendo em vista o papel normativo da Capes, firmado na Portaria Ministerial n. ${ }^{\circ} 1418$, de 23 de dezembro de 1998, de reconhecer os cursos de pós-graduação stricto sensu, estes prazos, de dois anos e quatro anos, tornaram-se parâmetros para os cursos de Pós-Graduação no país. Obviamente, comprometendo a condução de um genuíno Estudo de Caso, conforme orienta Yin.

Para seguir as recomendações de Yin acerca das teorias adotadas a priori, do Estudo de Caso piloto, elaboração de protocolo, triangulação de fontes, entrevistas, observações e outras técnicas de coleta de dados, são necessários muitos meses para o cumprimento de todas estas exigências, além de um relatório de pré-projeto muito bem estruturado e com um objeto de pesquisa muito bem definido, antes mesmo do início da pesquisa. Para o trabalho de mestrado de um pesquisador iniciante, podemos dizer que fica muito difícil a concepção, elaboração e conclusão de um Estudo de Caso, segundo os ensinamentos de Robert Yin, no tempo que the é concedido. No caso do doutorado, com a experiência acadêmica do pesquisador já adquirida no mestrado, é possível a elaboração de um Estudo de Caso único com enfoque incorporado, conforme detalha Yin em seu trabalho. Para uma abordagem múltipla e/ou holística, já seriam necessários tempo e recursos que ficam além da capacidade de um doutorando e da própria estrutura acadêmica atual.

Esta linha de raciocínio, aliás, nos leva ao segundo ponto que levantamos anteriormente: dinheiro. 0 recurso financeiro pode ser um impeditivo para o pesquisador elaborar um Estudo de Caso consistente e que cumpra as exigências propostas por Yin, até mesmo no nível de doutorado. As bolsas dos órgãos de pesquisas financiadoras são suficientes apenas para a modesta sobrevivência dos pesquisadores.

\section{CONSIDERAÇÕES FINAIS}

As observações acima não minimizam a importância do trabalho de Robert Yin e, tampouco, fazem uma profunda crítica ao sistema brasileiro de pesquisas acadêmicas. Apenas procuramos contextualizar o método à realidade que o país se encontra no estágio de desenvolvimento da estrutura e das pesquisas em Ciências Sociais Aplicadas.

Notamos que renomados pesquisadores e autores brasileiros sempre citam Yin, sem uma devida contextualização. Nas áreas de Administração e Ciências Contábeis são observadas dissertações, e mesmo teses, orientadas por um Estudo de Caso de duvidoso rigor metodológico-científico. A necessidade de contextualização moldará a viabilidade da execução de Estudos de Caso nas Ciências Sociais brasileiras.

É preciso, pois, uma revisão crítica da obra do autor e a elaboração de um estudo brasileiro para a melhor aplicação desta metodologia dentro da realidade nacional. Precisamos parar de repetir Yin e propor efetivamente uma metodologia nacional. Esta 
metodologia deve prever as limitações acadêmicas, contribuindo para uma orientação equilibrada de projetos de pesquisa.

Sugerimos também cautela na orientação para elaboração de Estudo de Caso para os pesquisadores brasileiros no nível de mestrado e doutorado. As limitações e dificuldades implicam a necessidade de um projeto viável para os pesquisadores, que permita levantar uma pesquisa de Estudo de Caso com uma preparação prévia e uma estrutura adequada. Para tanto, sugerimos que - quando muito - os projetos de mestrado tendam para um modelo de Estudo de Caso único com enfoque incorporado. No caso do doutorado, que oferece mais tempo e pressupõe um pesquisador mais experiente, pode-se sugerir, além da primeira hipótese, o modelo de Estudo de Caso único com enfoque holístico.

\section{REFERÊNCIAS}

BONOMA, Thomas V. Case Research in Marketing: Opportunities, Problems, and a Process. Journal of Marketing Research, v. XXII, p. 199-208, n. 22 may, 1985.

DONAIRE, Denis. A utilização do Estudo de Casos como método de pesquisa na área de administração. Revista IMES, São Caetano do Sul, 40, p. 9-19 , mai/ago, 1997.

GIL, A. C. . Metodologia do Ensino Superior. 4a.. ed. São Paulo: Atlas, 2005. v. 1. 121

GIL, A. C. Métodos e Técnicas de pesquisa social. São Paulo: Atlas, 1995.

GODOY, Arilda Schmidt. Pesquisa Qualitativa: tipos fundamentais. Revista de Administração de Empresas, v 26, 2, São Paulo, p20-29jul/ago, 1995.

LAZZARINI, Sérgio Giovannetti. Estudo de Caso: aplicabilidade e limitações do método para fins de pesquisa. Economia \& Empresa, , v 2, 4, São Paulo, out/dez, 1995..

MARTINS, Gilberto de Andrade. Estudo de Caso: Uma estratégia de pesquisa. São Paulo: Atlas, 2006.

PÁDUA, Elisabete Matallo Marchesini de. Metodologia da Pesquisa. 6.ed. Campinas: Papirus2000.

PORTARIA No 52, de 26 de setembro de 2002, da Coordenação de Aperfeiçoamento de Pessoal de Nível Superior (Capes), disponível em <http://www.unb.br/dpp/stricto/regulamento_demanda_social.pdf $>$. Acesso em: 11 jan. 2004.

Questões mais freqüentes sobre a Legislação da Pós-Graduação. Disponível em <http://www.capes.gov.br/Servicos/Legislacao/FAQ.htm>. Acesso em: 24 jan. 2004.

ROESCH, S. M. A. Projetos de Estágio e de Pesquisa em Administração. 2. ed. São Paulo: Editora Atlas, 1999.

SILVA, TD O caso do estudo de caso: a preferência metodológica na produção discente do núcleo de pós-graduação em administração da Universidade Federal da Bahia no período de 1999 a Julho de 2001. Caderno de Pesquisas em Administração/Programa de pósgraduação em Administração da FEA/USP. São Paulo: Universidade de São Paulo, v. 09, n. 3, p. $81-88$ jul./set. 2002

YIN, Robert K. Estudo de Caso, planejamento e métodos. 2.ed. São Paulo: Bookman, 2001. 


\title{
ENDEREÇO DOS AUTORES
}

\author{
Universidade de São Paulo \\ Faculdade de Economia Administração e Contabilidade \\ Departamento de Contabilidade e Atuária \\ Av. Prof. Luciano Gualberto, 908 - Prédio FEA III - Butantã \\ Sao Paulo, SP - Brasil \\ 05508-900
}

